\title{
Subfebrile fever after shoulder arthroscopy: Is it a complication or benign transient situation?
}

\author{
Ahmet Pişkinª, Ebru Kelsakab, Eyüp Çağatay Zengina*, Yüksel Bekc, Birol Gülmana, Murat Erdoğana \\ ${ }^{a}$ Department of Orthopedics and Traumatology, Faculty of Medicine, Ondokuz Mayls University, Samsun, Turkey \\ ${ }^{b}$ Department of Anesthesiology and Reanimation, Faculty of Medicine, Ondokuz Mayls University, Samsun, Turkey \\ ${ }^{c}$ Department of Biostatistic, Faculty of Medicine, Ondokuz Mayls University, Samsun, Turkey
}

\section{ARTICLE INFO}

\section{Article History}

Received

$12 / 11 / 2012$

Accepted

$16 / 12$ / 2012

\section{* Correspondence to:}

Eyüp Çağatay Zengin

Department of Orthopedics and

Traumatology, Faculty of Medicine,

Ondokuz Mayıs University,

Samsun, Turkey

e-mail: zengincagatay@hotmail.com

\section{Keywords:}

Impingement syndrome

Mini-open rotator cuff surgery

Postoperative complication

Shoulder arthroscopy

Subfebrile fever

\section{ABSTRACT}

We have evaluated 57 patients retrospectively who underwent arthroscopic and miniopen surgery in our clinic between 24.12.2009-31.12.2011. Twenty of 34 patients with impingement syndrome were treated by arthroscopic surgery and 14 of 34 patients were treated by arthroscopic and mini-open surgery. Seven of 23 patients with rotator cuff lesions were treated by arthroscopic surgery and 16 of 23 patients were treated by arthroscopic and mini-open surgery. Temperature over $37^{\circ} \mathrm{C}$ was considered as subfebrile temperature. The difference between the highest temperature observed in the postoperative period and the temperature in the preoperative period was calculated and termed as delta temperature. The delta temperature in the arthroscopically treated group was found $1.2 \pm$ $0.7^{\circ} \mathrm{C}$ and was $0.8 \pm 0.5^{\circ} \mathrm{C}$ in the other group $(\mathrm{p}<0.05)$. Time, gender and diagnosis were not a risk factor in the increase in the subfebrile temperature postoperatively. But the method of surgical treatment was found as a risk factor in the increase in subfebrile body temperature $(p<0.021)$. We have seen increase in the subfebril temperature in both arthroscopically alone and arthroscopic + mini-open treated patients but the rise in the subfebrile temperature was higher in the arthroscopically treated patients compared with the other group. The surgical method whether arthroscopy or arthroscopic+mini-open is a risk factor for an increase in post operative temperature.

J. Exp. Clin. Med., 2013; 30:19-21

\section{Introduction}

Shoulder arthroscopy is an increasingly popular method for treating ailments of the shoulder joint (Daruwalla et al., 2009). Complication rate has been reported at between $4.6 \%$ and 10.6\% (Marecek and Saltzman, 2010; Rains et al., 2011). Therefore, surgeons need to be vigilant about conditions predisposed to complications and take the necessary precautions. Although the literature reports intraoperative hypothermia during shoulder arthroscopy, there are no clinical studies reporting postoperative temperature changes (Kim et al., 2009; Board and Srinivasan, 2008). We have established temperature of body rising about $10^{\circ} \mathrm{C}$ in some cases. This study reports cases of early postoperative subfebrile fever associated with shoulder arthroscopy.

\section{Materials and methods}

Following approval of institutional ethical committee,
57 patients who had been treated with arthroscopy or arthroscopy+mini-open methods between 24.12.2009 and 31.12.2011 were retrospectively evaluated. Age, sex, gender, preoperative diagnosis, preoperative temperature, time taken for surgery, postoperative temperatures, hemodynamic data during and after surgery, and complications, were recorded. Body temperature data was acquired via a laser infrared thermometer. The temperature was measured every hour for six hours after the operation and once every two hours between six and 24 hours postoperatively. Temperatures from 36.5 to $37^{\circ} \mathrm{C}$ were accepted as normal, and those between $37-38^{\circ} \mathrm{C}$ were accepted as subfebrile. The differences between the highest preoperative and postoperative temperatures for each patient were recorded as delta tempature $(\Delta \mathrm{t})$. The operating room temperature was between $22-24^{\circ} \mathrm{C}$.

All patients were operated in the reclined sitting position. It was commenced with standard shoulder arthroscopy 
portals. Irrigations were done with plain $0.9 \% \mathrm{NaCl}$ solution kept at room temperature of approximately 22 to $24^{\circ} \mathrm{C}$. First generation cephalosporins were administered intravenously for prophylactic purposes. Patients operated for impingement were usually discharged the following day, and those operated for rotator cuff repair were discharged after two days. An average of 9 (2-10) liters of saline solution was used for irrigation, being lesser for the cases with impingement alone. An FMS DUO ${ }^{\circledR}$ pump was routinely used for that purpose in all cases. Intraoperative pressure was maintained at an average of $70(60-80) \mathrm{mmHg}$. Preoperative and postoperative white blood cell counts were also recorded.

The sample size of the study, 95\% confidence interval, $80 \%$ power, effect size of 0.8 units, 1 unit standard deviation values are calculated for groups of 27 patients were determined to be sufficient. The delta tempature data showed a normal distribution and were expressed as mean \pm SD. Preoperative temperatures were used as the covariate and the corrected postoperative temperatures and the corresponding graphs were obtained with ANCOVA. The gender, type and time of surgery and diagnosis of the patient were used for the evaluation of risk factors for temperature rise. Delta tempature, to comply with the normal distribution for age-paired samples, was analyzed with a t-test. A Mann-Whitney U test was performed preoperatively for temperature and time. Chisquare was used to compare categorical data. A significance level of $\alpha=0.05$ was used.

\section{Results}

Fifty-seven patients who have been treated by arthroscopy or arthroscopy+mini-open methods between 24.12.2009 and 31.12.2011 were retrospectively evaluated. Thirty four patients had impingement, and 23 had rotator cuff lesions. The surgical approaches to the patients are summarized in Table 1 .

\section{Table 1. Demographic data, diagnosis, preoperative and} delta temperature values

\begin{tabular}{lcc} 
& $\begin{array}{c}\text { Arthroscopic } \\
\text { Surgery } \\
(\mathbf{n = 2 7})\end{array}$ & $\begin{array}{c}\text { Arthroscopic+Mini } \\
\text { Open Surgery } \\
(\mathbf{n}=\mathbf{3 0})\end{array}$ \\
\hline Impingement/Rotator cuff tear & $20 / 7$ & $14 / 16$ \\
Age (year) & $54.3 \pm 11.7$ & $52.7 \pm 10.4$ \\
Gender (F/M) & $15 / 12$ & $17 / 13$ \\
Duration of surgery (min) & $93.0 \pm 35.3$ & $90.3 \pm 30.5$ \\
Preoperative temperature $\left({ }^{\circ} \mathrm{C}\right)$ & $36.1 \pm 0.1$ & $36.1 \pm 0.1$ \\
Delta temperature $\left({ }^{\circ} \mathrm{C}\right)$ & $1.2 \pm 0.7$ & $0.8 \pm 0.5^{*}$ \\
\hline
\end{tabular}

*; $<<0.05$ vs. Arthroscopic surgery

Preoperative body temperature, sex, age and time of surgery were not significantly different between arthroscopy and arthroscopy + mini-open groups $(p>0.05)$ (Table 1). The delta tempature, on the other hand, was significantly different, being $1.2 \pm 0.7^{\circ} \mathrm{C}$ in the arthroscopy group and $0.8 \pm 0.5^{\circ} \mathrm{C}$ in the mini open group $(\mathrm{p}<0.05)$. The delta tempature values of patients of individual groups are shown in Figure 1. Time, sex and diagnosis were not determined to be risk factors for postoperative subfebrile fever (Table 2).

However, surgical procedure was a significant risk factor $(p=0.021)$ (Fig. 2). Temperature elevation commenced at four hours postoperatively and was effectively resolved within six

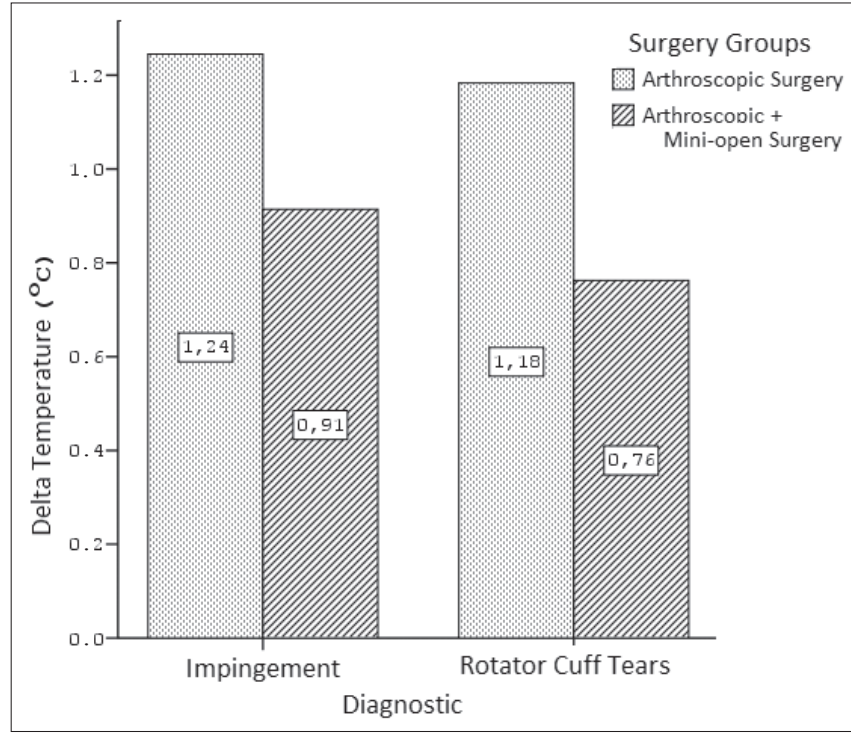

Fig. 1. Surgery patients according to the types the temperature change (delta temperature $\left.\left({ }^{\circ} \mathrm{C}\right)\right)$

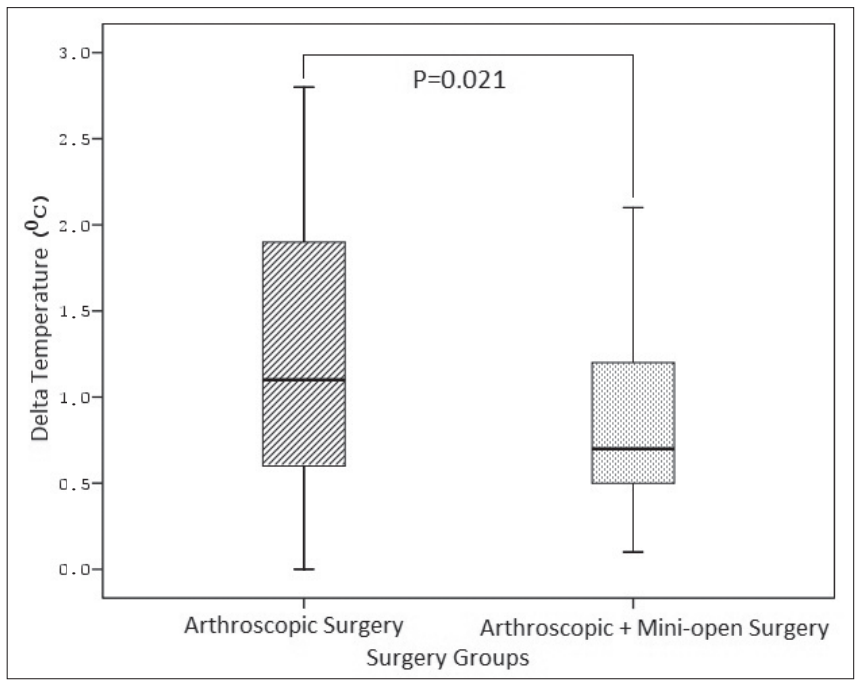

Fig. 2. Temperature change according to types of the surgery (delta temperature $\left.\left({ }^{\circ} \mathrm{C}\right)\right)$.

hours via oral or intravenous administration of paracetamol. There was no administration of additional drugs.

General anesthesia was administered to all patients in the same manner. In both groups, preoperative and postoperative white cell counts were $7.500 \pm 2.000 \mathrm{~mm}^{3}$ and $9.600 \pm 2.800$ $\mathrm{mm}^{3}$, respectively. No intraoperative or postoperative complications were encountered, there were no infections, no drug reactions preoperatively, no abnormal bleeding intraoperatively.

\section{Discussion}

The main finding of our study is that patients treated with arthroscopy alone had a higher tendency to develop postop-

\begin{tabular}{lcc}
\hline $\begin{array}{l}\text { Table 2. Gender, time and diagnosis effect on temperature } \\
\text { change (delta temperature) and the risk ratios }\end{array}$ \\
\hline & $\begin{array}{c}\text { Odds } \\
\text { ratio }\end{array}$ & $\begin{array}{c}\mathbf{9 5 \%} \\
\text { Confidence } \\
\text { interval }\end{array}$ \\
\hline Gender (M/F) & 1.146 & $0.391 ; 3.359$ \\
Duration of Surgery & 0.985 & $0.979 ; 1.012$ \\
Diagnosis (Impingement/Rotator Cuff Tear) & 1.510 & $0.509 ; 4.478$ \\
\hline
\end{tabular}


erative subfebrile fever. Time, sex and preoperative diagnosis did not influence the incidence of this condition.

There are a limited number of studies about temperature changes during shoulder arthroscopy (Board and Srinivasan, 2008; Kim et al., 2009), although not addressed as a complication. In their study investigating the influence of the heat of the irrigation fluid on the body temperature of shoulder arthroscopy patients, Kim et al. (2009) reported the incidence of hypothermia in patients in whom room temperature and warm saline was used to be $91.3 \%$ and $17.4 \%$, respectively. They also reported the influence of age on core temperature; however, their study did not include postoperative body temperature analysis. Our study's focus was on temperature changes in the early postoperative period, rather than those during surgery.

Body temperature elevation is the most common problem after operation (Pile, 2006). Temperature increasing within the first 48 hours is unlikely to be associated with infection since the onset of infectious fever is usually three days (Perlino, 2001; Willke and Tireli, 2009). The most common cause of non-infectious postoperative fever is surgical trauma. Other causes include drugs, blood transfusions, hematoma, pulmonary embolism and myocardial infarction (Ryan and Levy, 2003; Willke and Tireli, 2009). The cause of surgery related fever is the release of pyrogenic cytokines such as IL-1, IL-6, TNF and PG's, with IL-6 being reported to be exclusively associated with hyperthermia (Wortel et al., 1993; Pile et al., 2006). Which can occur in the absence of an infectious focus or agent (Perlino, 2001; Willke and Tireli, 2009).

The exact mechanisms which cause subfebrile fever in the early postoperative period are unclear. Unlike other open surgeries and knee arthroscopy, a much larger amount of irrigation solution needs to be used in shoulder arthroscopy, and it is known to leak out of the shoulder joint and disperse from the shoulder joint into surrounding tissues. We believe that fluids entrapped in tissues can induce pyrogenic cytokine release and thus induce hyperthermia. Reports in the literature indicate that extravased fluids following shoulder arthroscopy are absorbed within 12 hours (Venkat and Moon, 2009). Resolution of hyperthermia within 12 hours in all the cases in our study seem to support this mechanism. However, what we lack are serum levels of cytokine and recordings of intraoperative core and skin temperatures which would help either verify or dismiss this explanation.

None of the patients in our series developed wound related complications or any symptom suggesting an infection, so infection was ruled out as a cause of hyperthermia.

In our series, the average temperature rises in patients treated with arthroscopy alone, and arthroscopy+mini-open were $1.2 \pm 0.7^{\circ} \mathrm{C}$ and $0.8 \pm 0.5^{\circ} \mathrm{C}$, respectively. These values were not sufficiently high to diagnose clinical hyperthermia, so we labeled the condition "subfebrile fever" which is a selfresolving condition. It may be noticed by nurse checks in the ward but it does not usually influence the course of treatment. However, there are times when patients require antipyretic medication, as infrequently as once. Then again, since patients almost always have analgesic-anti-inflammatory agents ordered in their charts, a subfebrile fever can as well go unnoticed.

\section{Conclusion}

We recommend vigilant body temperature monitoring of shoulder arthroscopy patients. However, this is normally a transient self-limiting situation that does not require antipyretic medication. Even though our study's statistical power was sufficient to conclude that shoulder arthroscopy alone is more likely to cause subfebrile fever than shoulder arthroscopy+mini-open surgery. We still believe that analysis of larger series is needed to further confirm that conclusion.

\section{REFERENCES}

Board, T.N., Srinivasan, M.S., 2008. The effect of irrigation fluid temperature on core body temperature in arthroscopic shoulder surgery. Arch. Orthop. Traum. Surg. 128, 531-533.

Daruwalla, Z.J., Halpenny, M., Mullet, H., 2009. Day case shoulder surgery: Satisfactory pain control without regional anaesthesia. A prospective analysis of a perioperative control. Irish J. Med. Sci. 178, 209-213.

Kim, Y.S., Lee, J.Y., Yang, S.C., 2009. Comparative study of the influence of room-temperature and warmed fluid irrigation on body temparature in arthroscopic shoulder surgery. Arthroscopy. 25, 24-29.

Marecek, G.S., Saltzman, M.D., 2010. Complications in shoulder arthroscopy. Orthopedics. 33, 492-497.

Perlino, C.A., 2001. Postoperative fever. Med. Clin. N. Am. 85, 1141-1149.

Pile, J.C., 2006. Evaluating postoperative fever: A focused approach. Clev. Clin. J. Med. 73, 62-66.

Rains, D.D., Rooke, G.A., Wahl, C.J., 2011. Pathomechanisms and complications related to patient positioning and anesthesia during shoulder arthroscopy. Arthroscopy. 27, 532-541.

Ryan, M., Levy, M.M., 2003. Clinical review: Fever in intensive care unit patients. Crit. Care. 7, 221-225.

Venkat, G., Moon, Y.L., 2009. Upper airway compromise by extravasated fluid: A rare complication after arthroscopic repair of atrophic cuff tear. Orthopedics. 32, 48-50.

Willke, A., Tireli, M., 2009. Postoperatif ateş. ANKEM Derg. 23, 86-88.

Wortel, C.H., Van Deventer, S.J., Aarden, L.A., 1993. Interleukin-6 mediates host defense responses induced by abdominal surgery. Surgery. $114,564-570$. 